\title{
REFLEXIONES SOBRE HETERONORMATIVIDAD: LOS MODELOS Y REPRESENTACIONES DE FAMILIA EN UNA WEB DE SALUD DESDE LA MULTIMODALIDAD
}

\author{
Dra. (C) Cynthia Vergara Maldonado \\ Universidad Austral de Chile, Valdivia, Chile \\ cynthia.vergara@uach.cl \\ ORCID iD: https://orcid.org/0000-0001-8209-9304
}

Recibido el 25 de septiembre de 2019

Aceptado el 30 de abril de 2020

\begin{abstract}
Resumen
Las representaciones de familia que presuponen los Programas de Salud en Chile se difunden a través de dispositivos tecnológicos como la web, estas son creadas por hacedores de signos inmersos en una cultura con una carga histórica, social y política acerca de la familia basada en la construcción de un modelo de familia valido en una determinada sociedad chilena. Actualmente las relaciones afectivas y sexuales entre las personas incluyen formas de procrear naturales o tecnológicas de reproducción lo que tensiona el modelo de familia tradicional. Dicha sentencia proporciona cabida a otros modelos familiares (homoparentales) a diferencia de la familia reproductora de antaño basada en hombre y mujer como única forma. El presente artículo pretende una reflexión teórica acerca de los modelos de familia que son difundidos institucionalmente mediante las imágenes con su respectivo texto visual mediante la web. Se propone un análisis multimodal para abordar los textos visuales del Programa Chile Crece Contigo comenzando por un análisis desde la función representacional: actores, acciones y circunstancias (Kress y Leeuwen, 2006). Se concluye que las imágenes corresponden a su texto orientador y hacen referencia a la crianza como tema central, reforzando los roles de género en tanto madre, padre e hijo lo que presume heteronormatividad. Se reflexiona sobre las representaciones de la familia y su poder como institucionalizadora, además del potencial de los medios como la web para promover ideologías y representaciones de familia que permitan construir una imagen mental para generar nuevas representaciones de familia diferentes a la heteronormativa.
\end{abstract}

Palabras clave: multimodalidad, heteronormatividad, familia, programas de salud, internet. 


\title{
REFLECTIONS ON HETERONORMATIVITY: FAMILY MODELS AND REPRESENTATIONS ON A HEALTH WEB FROM MULTIMODALITY
}

\begin{abstract}
The family representations that Health Programs in Chile presuppose are disseminated through technological devices such as the web; these are created by makers of signs immersed in a culture with a historical, social and political load about the family based on the construction of a family model which is valid in a given Chilean society. Currently, affective and sexual relations between people include natural or technological forms of reproduction, which puts a strain on the traditional family model. This ruling provides room for other family models (homoparental) as opposed to the reproductive family of yesteryear based on men and women as only form. The present article aims at a theoretical reflection on the family models that are institutionally disseminated through images with their respective visual text through the web. It proposes a multimodal analysis to address the visual texts of the Chile Grows with You Program, starting with an analysis from the representational function: actors, actions and circumstances (Kress y Leeuwen, 2006). It is concluded that the images correspond to the guiding text and refer to upbringing as a central theme, reinforcing gender roles as mother, father and child, which assumes heteronormativity. It reflects on the representations of the family and its power as an institution, in addition to the potential of the media such as the web to promote ideologies and representations of family that allow the construction of a mental image to generate new representations of family different from the heteronormative one.
\end{abstract}

Keywords: multimodality, heteronormativity, family, health programs, internet. 
Introducción

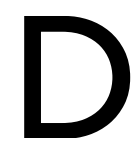

iversos modelos familiares han existido en la cultura Latinoamericana y, particularmente, en la cultura chilena, cuyos matices incluyen procesos de mestizaje y dominación (Pinto, 1990; Chacón et al., 2003; Mora, 2003; Valdés, 2007; Jocelyn, 2014). Estos modelos en la mayoría de las ocasiones no son semejantes al construido socialmente como aceptado y válido, lo que podría causar ciertas tensiones. Según el Instituto Nacional de Estadísticas (INE, 2017) en Chile el $54,1 \%$ de los hogares pertenece a familias nucleares (monoparentales o biparentales con 0 sin hijos), $19 \%$ a familias extendidas, $17,8 \%$ a familias unipersonales y no existen datos oficiales acerca de las familias homoparentales. Esta ausencia se relaciona con la capacidad del Estado de otorgar protección jurídica a la familia dentro del matrimonio, reconociéndolo como la base principal de la familia, siendo este, según la Constitución Política Chilena un contrato solemne entre un hombre y una mujer (Ministerio de Justicia, 2004). Aunque en el 2015 la Unión Civil, en alguna medida, ofrece protección jurídica para parejas del mismo sexo no incorpora derechos filiativos para con los hijos a diferencia del matrimonio. Por ello es necesario preguntarse si el Modelo de Familia que presenta la sociedad chilena en sus políticas públicas y particularmente en sus Programas de Salud, se condice con la realidad de las formaciones familiares de nuestra cultura. Dicho de otro modo, aquello que se nos enseña como significado de familia desde pequeños(as), ya sea en los juegos, en los cuentos, en el cine y en los libros, suele estar regulado por un conjunto de instituciones que determinan un discurso sobre la realidad de familia, el que comúnmente está asentado en la heteronormatividad.

Por lo anterior, las políticas públicas del Estado parecen actuar de acuerdo con un constructo de familia que es factible de controlar por el poder de las instituciones. Así, la familia no es solo una realidad construida por los individuos; la familia es controlada y, por esa vía, instituida por la sociedad (Bourdieu, 1997). Las instituciones -ligadas en este caso a la salud- elaboran sus propias políticas e instauran en la cultura chilena una visión unívoca de familia, amparándose en la unión del Estado con la Iglesia Católica imperante desde la época colonial de América.

Como señalan Berger y Luckmann se crea una realidad objetiva en la cultura y, asimismo, se crea una realidad institucionalizada que implanta, desde el poder, formas legítimas de familia en lo jurídico y en lo social. Adicionalmente, "este mismo cuerpo de conocimiento se transmite a la generación inmediata, se aprende como verdad objetiva en el curso de la socialización y de ese modo se internaliza como realidad subjetiva" (2001: 90).

Es necesario reflexionar sobre las imágenes y tensionar las representaciones de familia promovidas en los Programas de Salud, a partir de la heteronormatividad, siendo las tecnologías dispositivos de distribución de estas representaciones vía 
web. Por una parte, nos encontramos con la necesidad de un control social en sí mismo, con la exigencia de extender al mundo virtual el conjunto de actividades dirigidas a uniformar la conducta de los individuos con el objetivo de hacer respetar las normas y las expectativas del grupo social en un modelo familiar determinado. Por otra parte, encontramos la necesidad de desafiar, y tal vez modificar, las formas de poder; de oponerse a la voluntad de dominio de un actor o grupo social sobre otro (Massimo, 2011).

\section{UNA BREVE MIRADA HISTÓRICO-POLÍTICO -SOCIAL A LA FAMILIA}

Se distinguen a lo largo de la historia tres períodos claves de evolución en la familia: la familia tradicional, fundada en el contrato para preservar bienes; la familia moderna, bajo el alero del amor romántico, la división sexual del trabajo y la reproducción; y por último la familia contemporánea, centrada en una relación recíproca entre dos individuos que buscan relaciones íntimas y la expansión de la sexualidad (Roudinesco, 2007). De esta manera se puede distinguir como el concepto de familia tiene variantes en el tiempo, y solo últimamente incluye el ejercicio de la sexualidad como dimensión, aunque siempre reguladas por el poder institucional o social, lo que establece modelos de familia para seguir el orden simbólico y social.

En Chile, según Valdés, "el peso del Estado en la construcción de familia ha sido gravitante" (2007: 46), ya que con el tiempo varias funciones atribuidas a la familia han pasado al Estado, ganando terreno en la vida privada, en la estructura de la familia y en la vida conyugal. Esto explicaría la generalización de este tipo de familia nuclear bajo el alero de un Estado protector. Durkheim (1982) desarrolla una perspectiva funcionalista que podría aplicarse y explicar la realidad cultural dentro de la cual se cifra la construcción del modelo de familia prevalente en Chile desde la época de la Colonia. En este modelo, el patriarcado sustenta el origen del tipo de familia conyugal existente, el que está centrado en la familia moderna, y esta, a su vez, está fundada en el matrimonio, cuya protección en la actualidad se visualiza en la Constitución Chilena.

Sin embargo, la figura del padre ha estado ausente en las familias de América Latina durante siglos (Montecino, 1991; Valdés, 2007), de allí que la mujer haya terminado adquiriendo, en la práctica, un rol preponderante en la familia chilena. Es justamente el progreso lo que hace emerger la figura paterna, sobre todo en las clases altas, lo que también implica que la economía, las clases sociales, el género y la sexualidad son variables que repercuten en la construcción de la realidad asignada a la familia. Otros factores a tener en cuenta son la migración campociudad y la industrialización, pues ambos conllevan la configuración de la familia moderno-industrial (Valdés, 2007). Junto con ello, entre el siglo XIX y el siglo XX el Estado cobra una mayor importancia como interventor social. En lo jurídico se establece un campo regulatorio que promueve un ordenamiento familiar basado en el matrimonio, especialmente en las zonas urbanas, relegando al mundo rural a 
un marco de informalidad. Luego, a la par de la emigración se incentiva la división sexual del trabajo, acentuando condiciones desfavorables de salario y trato para las mujeres. Para Bourdieu (1998), la familia pasa a tener el papel principal en la reproducción de la dominación y de la visión masculina, por lo que en ella se imponen precozmente las primeras experiencias asociadas a la división sexual del trabajo. Esto acaba por enfatizar las diferencias de clase, reforzadas por las diferencias de roles de género en la familia. Engels (2005) alude a la familia individual moderna reparando en la esclavitud doméstica. Desde este enfoque, el hombre de la familia representa al sujeto burgués, en tanto la mujer representa en ella al proletariado. Según Valdés (2009) con la llegada del modelo neoliberal y la precariedad del empleo, la entrada de la mujer al trabajo y la globalización, el aumento de divorcios, nacimientos o uniones fuera del matrimonio, la sociedad sufre una diversificación familiar, aunque en la sociedad chilena se siguen conservando elementos de la familia tradicional y patrones de género lo que autora denomina una transitividad selectiva.

\subsection{La familia como construcción social: Sexualidad, heteronormatividad y género}

La necesidad de visibilizar los derechos de las mujeres se tornó evidente en los años 60, reduciendo las fronteras entre lo público y lo privado. Friedan (1963) describió en ese entonces la sensación de vacío emocional e insatisfacción en la vida de las mujeres, producto de una pasividad que les impidió ver la carga de la rutina familiar y el sometimiento experimentado sistemáticamente, lo que con el tiempo las llevaría a buscar un trabajo que no se adecuara a los estereotipos marcados por la maternidad social. En este escenario, el feminismo impulsó la lucha por el derecho a voto y por los derechos sexuales y reproductivos de las mujeres.

Junto con la mirada crítica al papel tradicional de la mujer, estas reivindicaciones ponen de manifiesto que existen diversos tipos de familia, los cuales difieren del modelo tradicional y cuya configuración está mediada, además, por el control de la natalidad, el aumento de las uniones no matrimoniales, la disputa por las libertades sexuales, entre otras condiciones que repercuten en la creación de realidades subjetivas. Por ende, a pesar de que existen modelos instaurados, las personas interpretan la familia de acuerdo con su propia realidad, y la forjan desde la óptica de los derechos que han conquistado. En específico, la batalla por los derechos sexuales y reproductivos ${ }^{1}$ elevaron el debate acerca de los derechos de las y los

1 La primera Declaración de los Derechos Sexuales fue proclamada en el XIII Congreso Mundial de Sexología, celebrado el 29 de junio de 1997 en Valencia, España. En el año 1999, durante el $14^{\circ}$ Congreso Mundial de Sexología en Hong Kong, estos derechos fueron revisados y aprobados por la Asamblea General de la Asociación Mundial para la Salud Sexual, destacando el derecho a la libertad y expresión sexual. 
desamparados por el sistema patriarcal, como es el caso de las mujeres, pero también de los grupos LGTBI (lesbianas, gays, travestis, transexuales, bisexuales, intersexuales), quienes igualmente han reclamado su derecho a legitimar sus respectivas familias. Por tanto, es propicio abordar estas temáticas desde el enfoque relacional de género como manera de ordenamiento de las prácticas sociales, que incluye las relaciones de poder, relaciones de producción y las relaciones ligadas a la sexualidad social (Connell,1987).

Varias teóricas feministas han contribuido a la lucha contra la heteronormatividad (Beauvoir, 1949; Rubin, 1986; Butler, 1990; Wittig, 1992; Falquet, 2004), suscitando y ampliando la discusión en torno al género. Desde este enfoque, el género es considerado como un constructo social que da lugar a la normalización de lo masculino y lo femenino, roles que se encuentran directamente relacionados con las formas y el funcionamiento de los cuerpos, instalando una coherencia binaria en la sociedad (Butler,1990). Esta idea presupone la perspectiva teórica del construccionismo social en lo que refiere a la constitución de la familia, desde una lógica binaria que contempla tanto la dualidad sexo-género, hombre-mujer, etc., como los roles asignados a cada uno. Para los Estudios de Género y la Teoría Feminista (Rubin, 1986; Rich, 1996), la familia va a ser criticada y denunciada como ámbito de dominación masculina por excelencia, donde el mandato patriarcal de ser madre opera como eje organizador de la vida de las mujeres.

La construcción social de familia, así como el orden sexual que le subyace, son aspectos clave en el desarrollo de las culturas. La sexualidad se ha expresado siempre de múltiples maneras, algunas aceptadas y otras vistas como abominables según la época. Por ello, lo que es admitido dentro de los parámetros sexuales depende invariablemente del contexto histórico. Por ejemplo, se ha documentado que en el tránsito que experimentó la familia desde el estado salvaje a la barbarie y finalmente a la civilización, los matrimonios por grupos y la promiscuidad sexual no eran motivo de sanción social (Morgan, 1987). A contar del régimen victoriano, "la sexualidad es cuidadosamente encerrada, se muda, la familia conyugal la confisca y la absorbe por entero en la seriedad de la función reproductora" (Foucault, 2005b: 9).

Sin embargo, hay que destacar que los cambios asociados a la concepción de la sexualidad no son lineales, ni tampoco evolucionan de modo uniforme en las culturas. La construcción de la familia varía culturalmente porque la familia como constructo social se ve influida por una serie de dispositivos de poder que actúan sobre el sexo, cuestión que, asimismo, constriñe el actuar de las demás instituciones del Estado para que estas puedan ejercer control en la sociedad. Por todo lo anterior, Foucault define a la familia como "la bisagra, el punto de enganche absolutamente indispensable para el funcionamiento mismo de todos los sistemas disciplinarios" (2005b:105). 
Estas sexualidades permitidas y prohibidas dentro de la familia responden a la construcción de la subjetividad dentro de la red vincular familiar, y adicionalmente se acoplan a las políticas sexuales vigentes, impactando en la reproducción social de los significados otorgados a las distintas modalidades sexuales (Burin y Meler, 1998). En el mundo burgués, la sexualidad afecta a la familia en su totalidad, fijando ciertas prácticas y confinándolas a ciertos espacios, ya que todas deben ser regladas incluyendo la sexualidad de las y los niños, adolescentes, ancianos, minusválidos, etc. (Foucault, 2005b).

En la familia suele darse por sentado que la heterosexualidad es la única orientación sexual válida, normal y socialmente aceptada, de allí que todo aquello que parezca diferente amenace con perturbar el orden social sexo/género impuesto, el cual se basa en la reproducción (Ventura, 2015). Por consiguiente, la familia educa a los sujetos rechazados por los sistemas disciplinarios, quienes retornan al núcleo familiar para poder ser vigilados y vueltos a la "normalidad". Foucault (2005a) concibe a la familia en cuanto modelo para explicar la organización de los psiquiátricos que mantienen su poder por la soberanía (poder divino), así la familia ejerce control y reclusión de los sujetos para su normalización, y si no se logra, la familia margina y abandona al sujeto dejándolo a su merced.

Dicho con otras palabras, en la sociedad prevalecen dispositivos de poder estructurados institucionalmente, los cuales se encargan de normativizar el sexo y la sexualidad en la familia, por un lado, y de aprobar o reprobar determinadas conductas sexuales, del otro. Es así como llega a instaurarse un modelo de familia basado en la heteronormatividad, y amparado en una trama estable de saber-poder conformada y promovida por el discurso y el no discurso (Foucault, 1978). Los discursos perpetúan representaciones de familia en lo material y en lo simbólico, considerando el plano discusivo y extra discursivo donde se desenvuelven los significados.

Por último, los roles de género también están estrechamente articulados al ejercicio de la sexualidad, sobre todo en lo que respecta a la mujer, con el objeto de cumplir con la reproducción de los miembros de la familia, pero no del disfrute y placer sexual de los mismos. Desde esta mirada sobre el placer, la familia se observa como una entidad que codifica el comportamiento sexual de las personas y asegura la mantención de la sociedad heteronormada. En este punto, Foucault señala que "en una época en que se explotaba sistemáticamente la fuerza de trabajo ¿se podía tolerar que fuera a dispersarse en los placeres, salvo aquellos, reducidos a un mínimo, que le permitiesen reproducirse?" (2005b:12). En este sentido, la familia pasa a ser no solo una productora de discursos sobre la sexualidad, sino que además se convierte en una de las esferas sociales desde donde se ejerce el podersaber sobre la sexualidad, y se erige como una de las instituciones sociales a partir de la cual se controla dicha sexualidad. Por lo anterior, la diversificación de los roles de género con la salida de la mujer al mundo laboral y a la esfera pública, hizo 
cuestionarse la esclavitud domestica propia que vivía la mujer en la familia conyugal, y con ello su papel en el ejercicio de su sexualidad.

Sin embargo, el control de la sexualidad ya no es un tema del individuo sino de la población, por ende, el Estado crea estrategias de control social para analizarla mediante tasas de natalidad, fecundación o anticoncepción, cautelando su finalidad reproductiva mediante las sexualidades prohibidas o permitidas, construyendo un discurso en torno al sexo (Burin y Meler, 1998). Dichas sexualidades prohibidas se trasladan al ámbito de la familia, cuyas restricciones no aceptan dentro de ella otra idea de familia diferente a la heteronormatividad. Así las familias homoparentales, su conformación, reproducción e inserción en las normas y roles familiares desestabilizan el orden simbólico hegemónico defendido por los grupos conservadores de la sociedad.

En consecuencia, lo que perturba a los conservadores ya no es la impugnación del modelo familiar sino, al contrario, la voluntad de someterse a él (Boccardi y Boccardi, 2011). El papel de los dispositivos tecnológicos como la inseminación artificial e incluso la adopción han permitido que dos hombres o dos mujeres puedan optar a formar una familia homoparental bajo las mismas lógicas de las familias heteronormadas fundada en la reproducción. Esto situación contribuye a establecer una sexualidad normalizada dentro de la institución de la familia, amenazante para el orden simbólico y social.

\section{MODELO DE SALUD FAMILIAR EN CHILE: ANTECEDENTES Y ENFOQUE DE LOS PROGRAMAS DE SALUD}

La incorporación del enfoque de Modelo de Salud Familiar (MSF) en Chile se remonta al año 1992, cuando el Ministerio de Salud (MINSAL) inicia la trasformación masiva de los consultorios en Centros de Salud Familiar (CESFAM). Este enfoque es de carácter sistémico y está asentado en principios que contemplan tanto al sujeto como a su entorno. En esta línea, varios autores han enfatizado la injerencia de la comunidad y la continuidad de la atención a lo largo del ciclo vital, comprendiendo al paciente como una persona única en relación con el sistema en donde se inserta y el apoyo social que recibe (Sherbourne y Stewart, 1991; McWhinney, 1996). En concordancia con ello, Evelyn Duvall (1977) describe un ciclo vital familiar en torno al cual la familia evoluciona y tiene sus propias etapas. Ahora bien, conviene señalar que estas teorías sobre la familia se posicionan desde lo heteronormativo y dan preponderancia a la reproducción, aspectos que siguen vigentes en la actualidad y rigen los Programas de Salud (PS).

Por consiguiente, en el ámbito de la salud se configuran numerosas normativas y directrices, las cuales, una vez traducidas a programas de uso público, involucran una serie de acciones implementadas por cada gobierno para mejorar las condiciones sanitarias y la calidad de vida de la población, a través de medidas que cautelan la promoción y la prevención durante el ciclo vital de las personas. Por esta 
razón, existen diferentes PS de acuerdo con el ciclo vital y la orientación específica que deben cubrir. En este sentido un conjunto de PS, por ende, está especialmente dirigido a la familia, algunos más característicos combinan texto con imágenes. Las imágenes se han incorporado a los PS para apoyar la promoción y la prevención. En un principio, las propagandas solo se visualizaban en periódicos y estas incluían la utilización de imágenes en blanco y negro (Dussaillant, 2016). Posteriormente, se crearon imágenes basadas en caricaturas, incorporadas en cartillas para las y los usuarios o en anuncios en televisión. Ya por los años 80 en Chile, con el auge del Virus de Inmune deficiencia Humana (V.I.H), las campañas incorporaron el uso de videos. Sin embargo, solamente a partir de los años 90 y principios de los 2000 comienzan a emplearse imágenes de personas reales en las campañas publicitarias y actualmente varios PS se distribuyen en páginas web, donde combinan imágenes y textos, para llegar a la mayoría de los usuarios de salud de manera gratuita.

\section{TEORÍA SOCIO-SEMIÓTICA Y MULTIMODALIDAD}

En los orígenes de la semiótica el concepto de signo tiene un papel preponderante (Leeuwen, 2005). Posteriormente, con el desarrollo de la semiótica social, el signo no solamente es considerado a partir de la unión del significado y el significante, sino que, siguiendo las contribuciones de Pierce, adquiere importancia la intención o motivación que aporta el creador de signos (Kress y Leeuwen, 2006). La noción de semiótica social fue acuñada por Michael Halliday (1979) en el marco de su teoría lingüística en esta dirección, Halliday (1985) va más allá del signo como entidad aislada. Este autor concibe el lenguaje no solo como un sistema de signos, sino que como recursos para la creación de significados. Estos significados emanan de varios sistemas semióticos a la vez (escrito, oral, visual, sonoro, gestual, etc.), siendo el texto una instancia donde estos sistemas se actualizan de acuerdo con las elecciones del hablante/escritor. Para dar cuenta de ello, Halliday (1985) plantea que el lenguaje se realiza a través de tres metafunciones: la ideacional, que se asocia a cómo los sujetos dotan de sentido el mundo que les rodea; la interpersonal, que remite a los intercambios que los sujetos llevan a cabo en la comunicación, y; la textual, que apunta a la forma en que sus mensajes son organizados.

Más tarde, Hodge y Kress (1988) proponen que la construcción de signos no se puede separar de la interacción social, de allí que la cultura y las ideologías de los sujetos sean proyectadas en los textos. En esta línea, la construcción de significados no solo se origina en el plano lingüístico, sino que se efectúa en diferentes modos semióticos, normalmente en combinación (verbal-visual, oral-gestual, visual-sonoro, etc.).

Kress y Leeuwen (2006) formalizan estas aproximaciones, acuñando la noción de multimodalidad mediante su propuesta de gramática visual. Para estos autores, la multimodalidad concierne al uso de varias modalidades semióticas para crear significados. Ellos retoman la teoría de las metafunciones del lenguaje para abordar 
una serie de textos que integran escritos e imágenes -procedentes de campos como la educación, el arte y la publicidad-, a las que denominan representacional, la cual se preocupa de la representación de participantes, eventos y circunstancias; interactiva, la cual se aboca a la relación entre la imagen y el observador, y; composicional, la cual se vincula a la disposición de los elementos en el texto.

\subsection{La imagen y el texto visual de familia como institucionalizadora}

Sobreentendemos que el objeto es solo la imagen visual y no las imágenes vinculadas a otras experiencias sensoriales (Abril, 2012). Pues en este sentido la imagen de familia, más allá de su componente visual, corresponde a un texto visual. Como señala el autor la palabra texto a de designar cualquier unidad de comunicación, por tanto, es así como entendemos que la representación de familia ya sea en diferentes modos semióticos (visual-textual) puede ejercer función en la cultura.

Hacia la segunda mitad del siglo XVIII la familia se convierte en el blanco de una magna empresa de aculturación médica centrada en el cuidado. En periódicos o diarios populares se masifican campañas de vacunas e higiene, con el propósito de esclarecer que la responsabilidad moral en los cuidados de salud y educación de los infantes pertenece a la familia. Además, mientras se avanza en estas políticas al interior de las familias, se abren instituciones para acoger a los huérfanos o distribuirlos en casas de familias, lo que se vuelve más rentable dado su escaso gasto doméstico. Es así como la familia medicalizada o medicalizadora contribuye al control social de la población, delineándose, como resultado, en un objeto de interés para el Estado, quien debe reforzar medidas en el ámbito de la salud poniendo énfasis en restricciones cada vez más autoritarias. Por lo tanto, la familia se instituye en un fenómeno relevante: la organización de la familia estrictamente parental funciona como soporte de la medicalización (Foucault, 1999). Por, tanto, sus representaciones son claves en la cultura de masas.

\section{METODOLOGÍA}

Metodología basada en una reflexión teórica desde la literatura revisada en relación con el corpus seleccionado. El corpus se compone de la portada de la página del Programa Chile Crece contigo ubicada en www.chilecrececontigo.cl con texto visual (imágenes y título orientador) referentes a familia, estas están compuestas de imágenes a color y textos de longitud variable (frases cortas). Dicho material es distribuido en formato papel en los establecimientos de Atención Primaria de Salud. Estos insumos son garantizados desde el Estado, llegan a las y los usuarios del sistema público, y también circulan en formato digital dentro del sistema privado, logrando un alcance potencialmente masivo.

Se seleccionarán imágenes que según la literatura revisada aluden a familia junto con su título orientador y se pueden observar principalmente los actores que la 
componen. Por tanto, se realiza una reflexión teórica acerca de las representaciones de familia promovidas por estos Programas. Las imágenes se proponen como material para un posterior análisis multimodal el cual se centra en un enfoque teórico metodológico proveniente de los Estudios Multimodales del Discurso (EMD), estos se abocan al análisis de los recursos semióticos que co-ocurren en la construcción de significados desde la relación imagen-título a partir de una matriz que incorpora categorías de la metafunción representacional: participantes, eventos y circunstancias (Kress y Leeuwen, 2006).

Con ello sabremos qué clase de actores (por ejemplo, las madres) realizan qué clase de acciones (por ejemplo, de cuidado), y en cuáles escenarios estas se llevan a cabo típicamente (por ejemplo, en el hogar) desde una aproximación representacional, clasificando estas imágenes en conceptuales o narrativas (donde los participantes interactúan con la mirada o por medio de vectores ) estas últimas, identificando el tipo de procesos o acción representada, por ejemplo; aquellos procesos materiales de acción (participante y meta) o reacción (reactor y fenómeno) que implican percepción visual. En los procesos materiales se distingue un actor, meta o un vector (línea imaginaria que emana del actor), esto demostrará los tipos de acciones lo que permite identificar los participantes y las circunstancias (Kress y Leeuwen, 2006).

\section{RESULTADOS}

El acceso de los textos visuales se realizó desde la página www.chilecrececontigo.cl. $\mathrm{Se}$ consideran las imágenes principales del banner que aluden a familia. Se distinguen una variedad de imágenes que dan cuenta de acciones materiales ya que suponen un cambio sobre la realidad representada. En todas las imágenes se distinguen actores y metas, e incluso puede existir más de un actor. Los vectores están formados por los brazos de los participantes y en varios casos por la mirada.

Las imágenes se despliegan con una gama de colores y centralizada en actores con forma de caricaturas, cuyas personas se distribuyen espacialmente en torno a la gestación y al recién nacido.

Las imágenes y textos están centralizadas ocupando gran parte de la página web. De estas desprendemos algunas descripciones comunes: las personas se agrupan bajo las funciones de protección y cuidados del recién nacido o nacida, la figura central siempre suelen ser los hijos o hijas. Los actores son mayoritariamente: hombre, mujer, niño o niña, o en efecto de mujer, mujer adulta y niños o niñas, cuya tez suele ser blanca en su mayoría. 
Fuente: Imagen portada Programa Chile Crece Contigo. Disponible en:

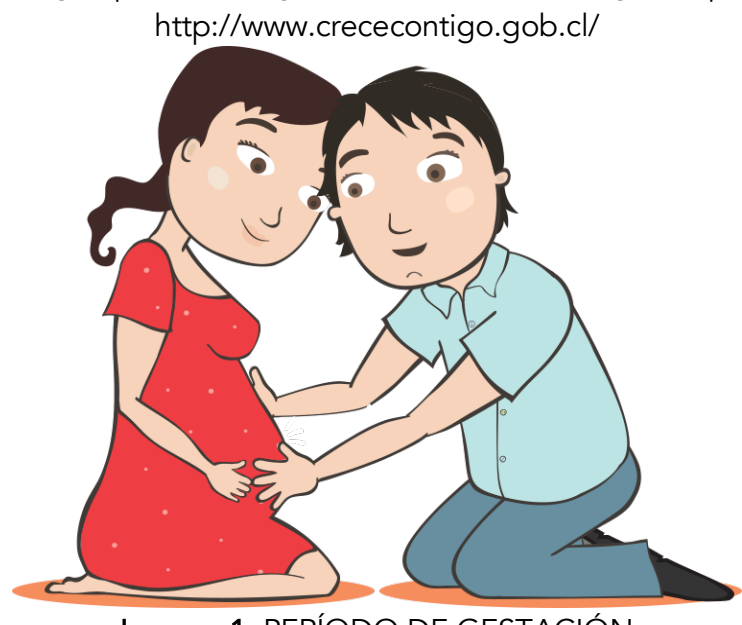

Imagen 1. PERÍODO DE GESTACIÓN

Esta imagen se compone de participantes interactivos, hombre y mujer en torno a la gestación (Imagen 1). El emplazamiento suele ser un fondo de color blanco, así la importancia radica en los actores que se encuentran en forma de caricatura, esta manera escogida por los hacedores de signos quizas para llegar al lector de estos programas de manera más lúdica, considerando que es un texto educativo. El reactor es el hombre quien fija la mirada hacia la mujer en este caso hacia la gestación y a su vez se forma un vector por la dirección de sus brazos hacia ella (materializada en el embarazo materno) que seria el fenómeno. Se observa en la imagen reacción de la madre, que a su vez se convierte en reactor (dirige la mirada a sí misma) hacia el fenómeno (gestación), que evoca su seguridad en el contexto en el proceso. El texto escrito de la imagen se denomina "período de gestación" que alude al tema central que concierne al rol de hombre como participante activo y el rol de la mujer como participante pasivo (quien recibe la acción) durante dicho período. La vestimenta de la mujer y el hombre alude a la asignada para su género, lo que da cuenta de la visibilidad de los roles de género y su identificación visual. La imagen hace referencia a una familia nuclear. 
Fuente: Imagen portada Programa Chile Crece Contigo. Disponible en:

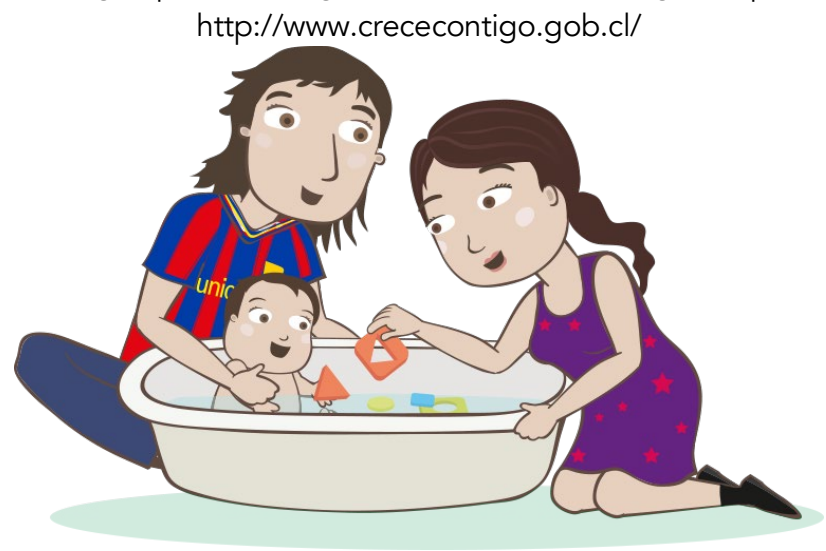

Imagen 2. PERÍODO DE O A 2 AÑOS

Se visualiza un hombre y una mujer con un niño (Imagen 2) en las circunstancias de cuidados, es decir, realizando acciones que contemplan el baño del recien nacido y su entretención. El emplazamiento es fondo blanco y priman los actores en forma de caricaturas. El hombre es un reactor ya que dirige la mirada a la mujer (fenómeno), ella no mantiene contacto visual con él sino que la mujer a su vez nuevamente (como la imagen 1) dirige la mirada hacia el niño o niña que actua como (fenómeno) al mismo tiempo conviertiendose ella en un reactor. Las acciones que mayoritaremente realizan son aquellas ligadas al cuidado del recien nacido o nacida, se visualiza la protección o unión de personas en torno a la crianza, el escrito de la imagen "período de 0 a 2 años" alude al niño o niña, y en la imagen se refuerza el rol del hombre y mujer que alude a los dos primeros años de vida del recien nacido.Ella y él con vestimenta acorde al género asignado.Ambos de tez blanca compartiendo la crianza, aunque la mujer con un rol más activo en dicha tarea. La imagen hace referencia a una familia nuclear. 
Fuente: Imagen portada Programa Chile Crece Contigo. Disponible en: http://www.crececontigo.gob.cl/

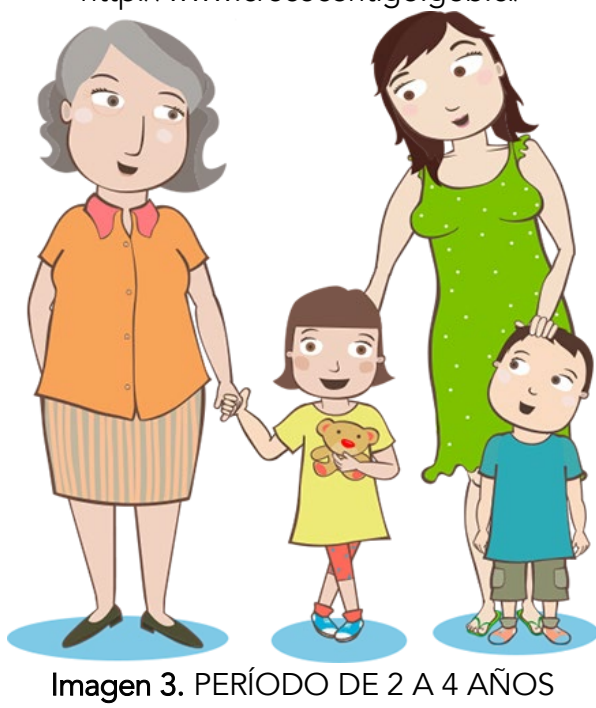

En esta imagen (Imagen 3) existen cuatro reactores, dos mujeres con diferente grupo etareo que podrían corresponder a madre y abuela, más un niño (vestimenta de polera y pantalon con colores oscuros) y una niña (pelo más largo, vestimenta con colores claros y un objeto "oso" en la mano). En esta imagen madre, abuela y niño se convierten en reactores, se forman vectores por el contacto cruzado de las miradas de dos participantes, niño y abuela (reactor y fenómeno a la vez). La madre es un reactor que forma un vector hacia la niña (fenómeno) que a su vez mira hacia fuera de la imagen (frente) donde no se presenta un fenómeno. El texto orientador de la imagen alude al "período de 2 a 4 años", nuevamente lo central en la imagen es el cuidado de los hijos, repartido en los roles de sujetos femeninos. Se destaca un fondo blanco y un piso de color para los participantes individualizados (excepto madre e hijo en un mismo círculo). Todos los participantes tienen tez blanca y ropa que alude a su género asignado sea hombre o mujer. La imagen hace referencia a una familia extendida.

Fuente: Imagen central (pie de página) portada Programa Chile Crece Contigo. Disponible en: http://www.crececontigo.gob.cl/)

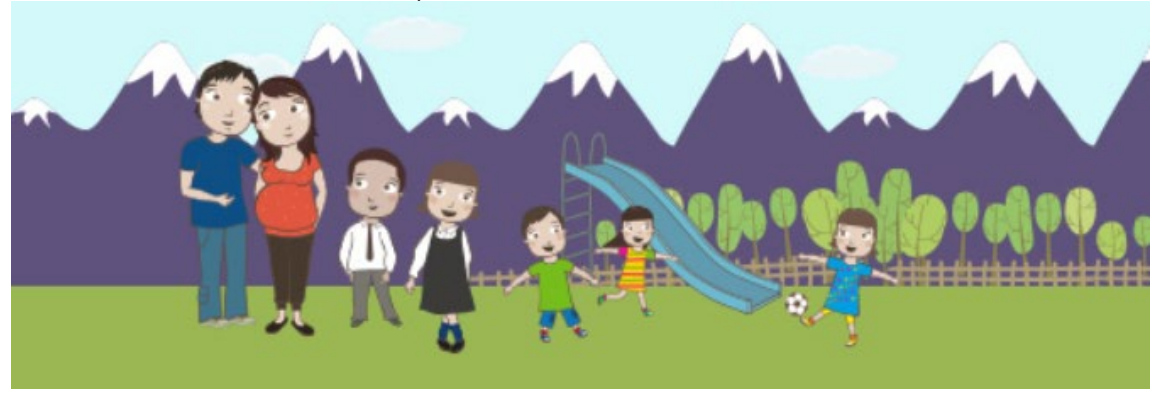

Imagen 4. PORTADA CHILE CRECE CONTIGO 
En esta imagen (Imagen 4) aparecen siete participantes, hombre y mujer son reactores y fenómenos a la vez, conforman intercambio de miradas, la representación de la mujer alude a un embarazo. Los niños como reactores mirando hacia el fenómeno que corresponde a la gestación se disponen de acuerdo a tamaño, primero a escolares (ropa diferenciada de hombre y mujer) como mayores y de mayor tamaño en la imagen, y los otros tres niños no escolarizados, según su vestimenta (interactúan solo entre ellos). En el juego (el niño con pantalón y pelo más corto, las niñas con vestimenta sin pantalón y pelo mediano tamaño). El emplazamiento alude a un parque de juegos, se comparte el juego de pelota entre hombres y mujeres (algo que destacar ya que este es asignado a varones). Se vislumbra la cordillera (geografía chilena) y vegetación, condice con el título orientador que dice "Chile crece Contigo. Se observan varios ciclos vitales (niños y adultos). La mayoría de los participantes tienen tez blanca y ropa que alude a su género asignado. La imagen hace referencia a una familia nuclear.

\section{REFLEXIONES FINALES}

Según Halliday (1985) la gramática la podemos concebir como una forma de representar la experiencia permitiendo construir como seres humanos una imagen mental de la realidad. En relación con la familia, todas las personas tienen una imagen de la propia familia o de una cercana que conocen basada en sus propias realidades, pero a su vez basada en una imagen mental de aquella familia ideal que por ejemplo en medios de comunicación han difundido de acuerdo con la cultura.

Las imágenes mentales se alimentan de parámetros previos que las experiencias y los aprendizajes han colaborado de acuerdo con las vivencias, la clase, el sexo, la orientación sexual, la identidad, la etnia, y el lugar donde habitamos que tiene una cultura determinada. Sin embargo, estas imágenes no suelen ser inocentes, estas realizadas por hacedores de signos que estar insertos, construidos cultural y socialmente por una comunidad (Krees y Leuween, 2006).

Estos hacedores de signos, a su vez pueden estar controlados por modelos hegemónicos que los orientan a realizar algunos signos en vez de otros, como puede ser el caso de los hacedores de signos de los Programas de Salud (PS) basados en el Modelo de Salud Familiar. Por tanto, las imágenes de familia promovidas en los modelos institucionales podrían diferir de los modelos de familia propios que habitualmente conforman las diversas familias en Chile pues no se consideran las familias homoparentales o de diversidad étnica. De ser así, las imágenes mentales que se tengan acerca de la familia se encontrarían en una constante tensión con las imágenes distribuidas en los PS con sus los modelos de familia institucionales.

En consecuencia observamos en los PS imágenes de familia que muchas veces se acompañan de un texto orientador, que puede o no coincidir, pero que en la mayoría de las veces coincide con las acciones que realizan los participantes de la imagen y reafirma los roles tradicionales, fundado en la diferencia de género dentro 
de la familia; los hombres se dedican a la protección de la familia o a educar lúdicamente a los niños(as) y las mujeres son las responsables de la crianza como sujetos activos en ella, con todo lo que implican los cuidados y labores para los niños(as), esto a lo largo de todo el sitio web, siendo esto una muestra de las imágenes. Lo anterior, manifiesta el poder potencial de los hacedores de signos para orientar o describir conductas a la sociedad a través de la imagen, que luego una a una de las imágenes formara la cultura de masas, y por ende una imagen de familia que promueve representaciones de familia basada en roles marcados y participantes determinados, distribuidas a través de dispositivos tecnológicos como la web. Es así como, el lenguaje es controlado en la actualidad por imperios culturales, tecnologizados, globalizados a nivel de comunicación de masas (Krees y Leuween, 2006)

En concreto, las imágenes de familia junto a su título orientador son realizadas por los hacedores de signos de manera que el mensaje pueda llegar a las familias que acuden a los centros de salud. Se utiliza un mensaje entendible, eso se evidencia por el uso de caricaturas, coloridas y en acciones concretas. Por tanto, los hacedores de signos eligen formas de expresión de familia que tienen en mente, formas que se consideren aptas (Krees y Leuween, 2006). Además, los PS incluyen ciertos participantes (hombre, mujer, niño(a)) como integrantes de la familia, tanto en circunstancias de cuidados o de educación, suponiendo que la mayoría de las familias que acuden a dichos centros de salud y a las cuales van dirigidos dichos PS son aquellas representadas por los hacedores de signos para lo cual crean imágenes, estableciendo los imaginarios colectivos que evocan dichas conformaciones familiares como modelos heteronormativos, utilizando dispositivos masivos y accesibles para los destinatarios como es el caso de la web.

Los hacedores de signos se mueven dentro de una cultura basada en la heteronormatividad que las instituciones y la cultura chilena aún profesan, gracias a las estructuras de poder y a los modelos de familia insertos y permitidos, siendo estos modelos familiares aquellos mayoritariamente visibilizados en los centros de salud. Por tanto, los PS y sus centros de salud acogen y promueven que dichas familias basadas en la heteronormatividad acceden a sus prestaciones de salud en un contexto particular de único imaginario social de familia. Así, la comunicación requiere que los participantes hagan sus mensajes entendibles al máximo de un contexto particular, dentro de estructuras sociales marcadas por relaciones de poder (Krees y Leuween, 2006)

Krees y Leuween (2006) señalan que la comunicación visual siempre está codificada, ya que conocemos el código y solo nos parece transparente porque conocemos dicho código. La creación de códigos se puede remontar a actividades realizadas a edades tempranas en el contexto de las instituciones de educación, donde nos hacen dibujar a la propia familia, estas imágenes suelen ser rudimentarias pero entrenan las representaciones de familia que cada niño(a) tiene y que posteriormente se irán nutriendo de las experiencias vividas y formando los códigos 
que reconocemos en diferentes imágenes que aluden a la familia, por tanto, cuando los PS promueven representaciones de familia, estos códigos son reconocidos por miembros de la cultura.

El papel de la web en la distribución de imágenes es crucial para comprender como dichas imágenes digitales están disponibles y accesibles para los usuarios de los PS, y pueden potenciar imaginarios de familia o representaciones de familia que posteriormente pueden ser reproducidas como verdades acerca de lo considerado como familia en la sociedad chilena. Por tanto, es posible pensar en las imágenes de familia como formas de posiciones ideológicas, es decir, creencias socialmente compartidas que perpetúan ciertos modelos de familia por sobre otros, dando valor a una forma determinada de familia, y no otorgando cabida a nuevas formas, sino solo a aquellas basadas en lo heteronormativo. Sin embargo, las ideologías se integran paulatinamente en los grupos y así se pueden desintegrar gradualmente constituyendo, las imágenes, una oportunidad para promover diversidad familiar.

Krees y Leuween (2006) señalan que las imágenes están conectadas a los intereses de las instituciones sociales en las que han sido reproducidas. Por lo cual, es posible tensionar el modelo de familia heteronormativo que representan dichos PS, considerando que estas imágenes son creadas por hacedores de signos y distribuidas por instituciones sociales de salud a través de dispositivos tecnológicos como la web. Así, el marco institucional de salud parece velar por un modelo de familia en particular, convirtiéndose en un dispositivo de poder. En consecuencia, se hace necesario reflexionar sobre las representaciones de familia y la heteronormatividad a través de enfoques multidisciplinarios que impliquen un análisis multimodal como desafío.

\section{FINANCIAMIENTO}

Este trabajo es financiado por la Agencia Nacional de Investigación y Desarrollo, ANID-Chile, Programa de Investigación Asociativa, a través del Proyecto Anillo titulado: "Converging Horizons: Production, Mediation, Reception and Effects of Representations of Marginality", PIA-ANID/ANILLOS SOC180045. 


\section{Referencias bibliográficas}

ABRIL, G. (2012): Tres dimensiones del texto y de la cultura visual. IC-Revista Científica de Información y Comunicación, 9, pp.15-35.

BEAUVOIR, S. (1949): El segundo sexo. Los hechos y los mitos. Buenos Aires, Siglo $X X I$.

BERGER, P. y LUCKMANN, T. (2001): La construcción social de la Realidad. Buenos Aires: Amorrortu Editores.

BOCCARDI, F y BOCCARDI, P. (2011): Tensiones sexuales de la familia. Una lectura de las configuraciones de la familia en el discurso social argentino. Perspectivas de la Comunicación, 4 (2), pp. 68-78.

BOURDIEU, P. (1997): Razones prácticas sobre la teoría de la acción. Barcelona: Anagrama.

(1998): La dominación masculina. Barcelona: Anagrama.

BURIN, M. y MELER, I. (1998): Género y familia: Poder, amor y sexualidad en la construcción de la subjetividad. Buenos Aires: Paidós.

BUTLER, J. (1990): El género en disputa: El feminismo y la subversión de la identidad. Barcelona: Paidós.

CHACÓN, F., IRIGOYEN, A., MESQUITA, E., y LOZANO, T. (Coords.) (2003): Sin distancias: Familia y tendencias historiográficas en el siglo XX. Murcia: Universidad de Murcia.

CONNELL, R. (1987): Gender and power. Society, the person and sexual politics. Cambridge: Polity Press.

DURKHEIM, E. (1892): La famille conyugale. En DURKHEIM, E. (Ed.), Textes 3. Fonctions et institutions. París: Les Ëditions du Minuit, pp. 35-49.

DUSSAILLANT, J. (2016): La publicidad para la salud infantil en la prensa chilena (1860-1920). Cuadernos de historia (Santiago), 45, pp. 89-115. Disponible en: https://dx.doi.org/10.4067/S0719-12432016000200004

DUVALL, E. (1977): Marriage and family development. New York, Lippincott.

ENGELS, F. (2005): El origen de la Familia, la propiedad privada y el Estado. España: Ediciones Fundación Federico Engels. 
FALQUET, J. (2004): Breve reseña de algunas teóricas lésbicas. México D.F.: Editorial fem-e -libros.

FOUCAULT, M. (1978): Dispositivos de poder. Berlín: Merve. (1999): Estrategias de poder. Obras esenciales (Vol. II). Barcelona: Paidós. (2005a). El poder psiquiátrico. Curso 1973-1974. Buenos Aires: FCE. $\mathrm{XXI}$. (2005b): Historia de la sexualidad1. La voluntad del saber. Buenos Aires: Siglo FRIEDAN, B. (1963): La mística de la Feminidad. Madrid: Cátedra.

HALLIDAY, M.A.K. (1979): El lenguaje como semiótica social. México D.F.: FCE. (1985): An Introduction to Functional Grammar. London: Arnold.

HODGE, R., y KRESS, G. (1988): Social semiotics. Cambridge: Polity Press.

INSTITUTO NACIONAL DE ESTADISTICAS (INE) (2017). Síntesis de resultados Censo 2017. Disponible en: https://www.censo2017.cl/descargas/home/sintesisde-resultados-censo2017.pdf

JOCELYN, A. (2014): Historia General de Chile III: Amos, señores y patricios. Santiago: Editorial Sudamericana.

KRESS, G., y LEEUWEN, T. (2006): Reading images. The grammar of visual design (2nd. Ed.). London: Routledge.

LEEUWEN, T. (2005): Introducing Social Semiotics. London/New York: Routledge.

MASSIMO, R. (2011). Internet y control social, entre rizoma y gran hermano. Perspectivas de la Comunicación, 4 (1), pp. 42-52.

MCWHINNEY, I. (1996): Medicina de familia. Madrid: Mosby/Doyma Libros.

MINISTERIO DE JUSTICIA (2004). Establece nueva Ley de Matrimonio Civil (Ley 19947). Gobierno de Chile. Disponible en:

https://www.leychile.cl/Navegar?idNorma $=225128$

MONTECINO, S. (1991): Madres y huachos. Alegorías del mestizaje chileno. Santiago: CEDEM. 
MORA, C. (2003): Desigualdad en Chile: La continua relevancia del género. Santiago: Universidad Alberto Hurtado.

MORGAN, L. (1987). La sociedad primitiva. Madrid: Edymon.

PINTO, S. (1990): Matrimonio y mestizaje en Chile colonial. Santiago: Universidad de Chile.

$\mathrm{RICH}, \mathrm{A}$. (1996): Compulsory heterosexuality and lesbian existence. Signs, 5 (4), pp. 631-660.

ROUDINESCO, E. (2007): La familia en desorden. Buenos Aires: Fondo de Cultura Económica.

RUBIN, G. (1986): El tráfico de mujeres: Notas sobre la "economía política" del sexo. Nueva Antropología, 8 (30), pp. 95-145.

SHERBOURNE, C., y STEWART, A. (1991): The MOS social support survey. Social Science \& Medicine, 32 (6), pp. 705-714.

VALDÉS, X. (2007): La vida en común: Familia y vida privada en Chile y el medio rural en la segunda mitad del siglo XX. Santiago: LOM.

(2009): Metamorfosis de la Familia y la vida privada. Cambios y tendencias en Chile. Concepción: Universidad del Bío-Bío.

VENTURA, R. (2015). La sexualidad mediada: Estudio de la heteronormatividad en los informativos de televisión. (Tesis Doctoral). Universitat Pompeu Fabra, España.

WITTIG, M. (2016 [1992]): El pensamiento heterosexual y otros ensayos (3ra Ed.). Barcelona/Madrid: Egales Editorial. 